\title{
An Exploration on Process-oriented Model of Translation Teaching among Chinese Colleges in the Information Era
}

\author{
Yuanzhen Wu \\ Gongqing College \\ Nanchang University \\ Gongqing, China
}

\author{
Shijun Liu \\ Gongqing College \\ Nanchang University \\ Gongqing, China
}

\begin{abstract}
Based on the Process-oriented model, the paper tries to make an exploration on effective translation teaching among Chinese colleges. It mainly puts forward two teaching approaches, that is, the application of translation workshop and reflective journal writing. Also how to apply the teaching model in the Information era is discussed in order to promote translation teaching reform in accordance to the demand of society.
\end{abstract}

Keywords-process-oriented; translation teaching; Chinese colleges; information era

\section{INTRODUCTION}

Hatim refers to the word translation as both the process of translating and its product, including the researches on translation as well (Hatim, 2001: 3). There exist mainly two models of college translation teaching in China nowadays, that is, product-oriented model and process-oriented model. The former lays emphasis on the product of translation, especially the only and standard one, which is a traditional teaching model, while the latter focuses on the procedures from preparing to accomplishing a translating task, and a translator's thinking process in translating (Bell 2001). In this paper, it refers to the process of translating; in other words, how translating is operated, i.e. what difficulties are met, what skills are employed during translating and how the translation comes into being, etc. are taken into account.

Kiraly puts forward a Social Constructivist approach to translator education based on theories of Social Constructivism, maintaining that learners should construct knowledge actively instead of receiving knowledge passively, which is learner-centered (Kiraly 2000). Furthermore, the social interaction theory stresses that learning comes into effectiveness through interaction among learners of different levels. Drawing from this perspective, in the field of translation learning, the skills and abilities are to be polished through active construction, involving cooperation and interaction among learners, which in turn throw light on the process-oriented model for translation teaching.

Undoubtedly, with the advent of information era, our life is closely connected with advanced technology and teaching is no exception, which adheres to the notion of Education information system that refers to a self-organized and selfadapted system. It involves the interaction between information human beings, and the information environment, while the essential element is information rather than educational software or other material products in such interaction (Lucas \&Wilson 2008). Therefore, how to make the best of modern information technologies in effective translation teaching is to be explored in this paper.

\section{APPROACHES OF PROCESS-ORIENTED TEACHING MODEL}

The teaching objective of translation is to cultivate students' communicative training competence. The following are what need to be developed first: selfconfidence, self-awareness, professionalism, expert behavior and ability to objectively justify translation decisions (Colina, 2009). They are inclined to be achieved during the process of translating learning, involving knowledge construction and sharing, peer cooperation, interaction and negotiation.

\section{A. Translation Workshop}

In traditional Chinese translation teaching classroom, teachers focus on various translating skills and students learn to apply them to do the task of translating, followed by comparison with standard version of translation, which is a product-oriented teaching model, turning students' attention solely on some mistakes they make. Nevertheless, it is commonly acknowledged that rarely would an individual reach the same translation version compared with the referred one. Therefore, this product-oriented model involves the steps of learning, doing tasks and correcting mistakes, in which the teacher spend most of the time explaining language points and translation skills, that is, students tend to be passive learners.

By contrast, translation workshop is a form of processoriented model, in which the task of translating is accomplished through cooperation among group members, with teachers as guidance, via the aid of multiple translating tools; a commonly satisfied translation is negotiated by discussions among groups and their members. During such process, the teacher makes explanation and comments on 
some translation strategies, by which means the major participation of students in class and interaction among students, between students and teachers are achieved. It is through such process that the abilities of understanding and translating are constructed subconsciously and effectively without paying too much attention on correcting mistakes on their own translation compared with the so-called standard version since it is well-known to all that there could be differing translated versions of stylistic genres for the same text according to translators' interpretations.

Additionally, the model of translation model is carried out in accordance to some translating projects conducted in markets, closely related to the reality of society, for example, translating texts in aspects of economy, medicine and education, etc. Traditional artificial translation services could no longer satisfy the increasing demands of society while learning how to cooperate with team members and make the best of translation workspace tends to lay a solid foundation for students' future work. When students note that what they have learned can be applied into practice, and from practice they can learn more, it can also arouse their passion in learning, realizing that knowledge learned is useful and effective.

\section{B. Reflective Journal Writing}

Through discussing, negotiating and interacting with group members, students are inclined to correct their mistakes 1, and mark down right words or expressions, which undoubtedly indicate that students would master a correct translating skill or a useful expression. Yet, simply taking them down is not enough, it is appropriate that some sort of evaluation, i.e. by themselves or others is added. In other words, following a translation task, a journal should be a reflective one and in detail, including what problems are met, how they are solved and what strategies are employed, etc. Evaluation of translation among peers should tell the accuracy of meaning, thought and culture conveying, the readability and naturalness of target language and some creative methods to deal with intercultural inequivalence ( Szczyrbak, 2008: 72-73 ).

According to a survey conducted by Liao Suyun (2012), $72.14 \%$ students consult other students to write journals; $67.21 \%$ students discuss what they write with classmates in order to learn from others and improve them. By this means, journal writing stimulates students' autonomous learning and cooperative learning.

Journal writing is not restricted to summary or review of what has been learned in translation. Not only does it refer to reviewing the past, but also it offers inspiration to the following tasks or projects. As to the content of journal writing, $55.84 \%$ is about difficulties in translation and ways to deal with them; $17.92 \%$ involves application in translation theories; $17.41 \%$ is related to adaptation of learning strategies (Liao 2012). The other major benefits of journal

Note here that mistakes aren't necessarily wrong or unacceptable in grammar, even though sometimes it may be the case. Yet to some, it could refer to inconformity to the standard version of translation due to different interpretations of translators. writing could be listed as follows: $26.14 \%$ get to know their strengths and shortcomings in translation; 20\% deepen their understanding to stylistic genres and translation theories; $15.23 \%$ polish their skills on employing network resources and some tools; other benefits include improving interests in translation learning and more opportunities in discussion and practices of translation. From this perspective, the journal writing is a reflective one, reflecting one's thoughts and thinking pattern in the process of translating.

\section{APPLICATION IN THE INFORMATION ERA}

There is no denying that texts or materials in translation derive from the society and in turn translation serves the society, thus closely interconnected with the current Information era we live in. As to the translating process itself, it involves understanding the original text and producing a new text in target language (House 2009). Apparently, the information processing needs to be aided by advanced technologies, which can be reflected in smart phones that almost every college student owns. Opening and sharing are two major defining characteristics in the Internet era and language teaching is no exception; it could be open and interactive.

The popularity of cell phones is a two-side sword. On one side, it is a common threat for teachers on the ground that too much teaching and little participation in class discourage students' passion for learning, with more phubbers appearing in class due to more addiction to cell phones; A survey on the phenomenon of playing cell phones in class indicates that more than $90 \%$ students acknowledge that they have played cell phones in class, with $49 \%$ often, $37 \%$ sometimes, $12 \%$ occasionally, and only $2 \%$ never. Among the $49 \%$, over $60 \%$ check information in cell phones within every ten minutes ( $\mathrm{Li}$ 2016).

On the other side, a smart phone with advanced functions is a powerful tool for obtaining resources for study instead of simply playing games. Such online translating software as Lingos Translator, Google Translate and Youdao Dictionary, etc. serve as powerful tools in offering a considerable number of vocabularies for us to refer. In translation workshop, teachers deliver materials through the platform of microblog or WeChat to students to get well prepared beforehand, the content of which consists of texts need to be translated, related pictures, videos and other background information. Students in groups with four to five members finish the task of translation include discussion and PPT making within the group, and uploading the whole process to QQ or WeChat group online; during the class, a representative from each group report their translated text to the class, including the skills and methods employed to deal with the text. After negotiations of groups, students vote their satisfactory version of translation in the We-media.

Furthermore, reflective journal can also be written on QQ or WeChat group online, sharing their different thoughts and ideas in understanding and translating the same text and learning from each other. Therefore, translation workshop and reflective journal writing could be carried out more 
conveniently online while the function of offline class teaching should not be neglected.

\section{CONCLUSION}

As is revealed from above, active participation and major role in class turns students' attention to effective learning and ability development, during which process the capacity of cooperation and negotiation is cultivated and also their interest in translation is aroused.

The process-oriented teaching model focuses on each step in translation, analysis of texts and improvement of translation; it is learner-centered in that it cultivates students' potential in autonomous learning and self-confidence in translation; in the translating process, analyzing and solving problems, communicating and negotiating with others helps build the awareness of responsibility as qualified translators. And the two approaches illustrated above, translation workshop and reflective journal writing, are a whole, interrelated with each other and should not be separated in practice.

Even though it seems that in this paper the processoriented model emphasizes sharply the significance of the process of students in translation, it doesn't deny the guidance of teachers; on the contrary, teachers in effect spend more time in preparing more attractive topics in class and evaluating different versions of translations and journals, not the other way around. Besides, students are taught how to evaluate different versions of translation during class, search related information and useful data required for translation before and after class. From this perspective, it is by no means exaggerating to say that the teacher in such translation class works as a guide, organizer, promoter, regulator and mediator, etc.

To conclude, translation is the product of the process of translation; without the process, there would be no product of translation, to some extent. The process encompasses a wider scope of connotation: the objective procedures from the beginning to the end and subjective thinking process one undergoes in translation.

\section{REFERENCES}

[1] Bell, R.T. Translation and Translating: Theory and Practice. London \& New York: Longman, 2001.

[2] Colina,S. Translation Teaching-From Research to the Classroom: A Handbook for Teachers. Shanghai: Shanghai Foreign Language Education Press, 2009.

[3] Hatim, B. Teaching and Researching Translation. Essex: Pearson Education Limited, 2001.

[4] Juliane House. Translation.Oxford: Oxford University Press, p.20, 2009.

[5] Kiraly, D. A Social Constructivist Approach to Translator Education: Empowerment from Theory to Practice. Manchester: St Jerome Publishing, 2000.

[6] Lucas MT \& MA Wilson, On the evolution of education information system and the formation of education information ecosystem, Distance Education in China, vol. 2, no.3, pp.203-218, 2008.
[7] Szczyrbak, M. Reflections on teaching business and legal translation to polish undergraduate students. SKASE Journal Of Translation and Interpretation[online].vol.3,pp.65-81,2008.

[8] Li An-na, On Construction of the Translation Teaching Model in the Information Era, Heilongjiang Researches on Higher Education, vol.4, pp. 168-170, 2016.

[9] Liao Suyun, The effect of journals on the cultivation of translation competence, Chinese Vocational and Technical Education, vol.32, pp. 90-92, 2012. 